\title{
Inhibition Has Little Effect on Response Latencies in the Inferior Colliculus
}

\author{
Zoltan M. Fuzessery, ${ }^{1}$ Jeffrey J. Wenstrup, ${ }^{2}$ Jim C. Hall, $^{3}$ and Scott Leroy ${ }^{2}$ \\ ${ }^{1}$ Department of Zoology and Physiology, University of Wyoming, Laramie, WY 82071, USA \\ ${ }^{2}$ Department of Neurobiology and Pharmacology, Northeastern Ohio Universities College of Medicine, Rootstown, \\ $\mathrm{OH}$ 44272, USA \\ ${ }^{3}$ Department of Biochemistry and Cellular and Molecular Biology, University of Tennessee, Knoxville, TN 37996, USA
}

Received: 27 November 2001; Accepted: 3 June 2002; Online publication: 19 August 2002

\section{ABSTRACT}

The inferior colliculi of all mammals are characterized by a wide range of first-spike response latencies that can greatly exceed the minimum time required for the transmission of input through the lower brainstem. The mechanisms that account for long response latencies of up to $50 \mathrm{~ms}$ are unclear, but one hypothesis is that an early inhibition plays a role in shaping latency. To test this hypothesis, response latencies were measured in the inferior colliculi of the pallid and mustached bats before and during the blockade of GABAa and glycine receptors. The effect of blocking inhibition on response latency was compared under stimulus conditions that produced the shortest latency in the predrug condition. Multibarrel "piggyback" electrodes were used to iontophoretically apply bicuculline and strychnine sequentially while recording from single neurons. Predrug latencies ranged from 9 to $26 \mathrm{~ms}$ in the pallid bat and from 4 to $17 \mathrm{~ms}$ in the mustached bat. Despite large increases in response magnitude and response duration following disinhibition, the blockade of inhibitory receptors had modest effects on response latency. In the pallid bat, blocking GABA receptors produced latency changes that ranged from -3.8 to $+0.2 \mathrm{~ms}$, while blocking glycine receptors produced changes from -0.1 to $+1.7 \mathrm{~ms}$. Similarly, in the mustached bat, blocking GABA receptors caused changes ranging from -10.3 to $+1.4 \mathrm{~ms}$; blocking glycine receptors in

Correspondence to: Zoltan M. Fuzessery • Department of Zoology and Physiology • University of Wyoming - Laramie, WY 82071. Telephone: (307) 766-4207; fax: (307) 766-5625; email: zmf@uwyo.edu the mustached bat caused changes from -3.6 to +1.0 $\mathrm{ms}$. The large change of $-10.3 \mathrm{~ms}$ was an exception. In both species, the majority of neurons showed changes of $<1 \mathrm{~ms}$. We conclude that a fast, early inhibitory input does not appear to play a significant role in shaping the wide range of response latencies present in the inferior colliculi of mustached and pallid bats.

Keywords: inferior colliculus, response latency, GABA, glycine

\section{INTRODUCTION}

The ranges of response latencies of neurons in the mammalian inferior colliculus (IC) are remarkably similar across species, despite the fact that their brain sizes differ by orders of magnitude. In the rat, guinea pig, cat, and bats, the majority of IC neurons have response latencies between 5 and $50 \mathrm{~ms}$ (Kitzes et al. 1978; Jen and Schlegel 1982; Harrison and Palmer 1984; Langner et al. 1987; Park and Pollak 1993; Ehert and Romand 1992; Fitzpatrick et al. 1995; Le Beau et al. 1996; Lu et al. 1997; Ferragamo et al. 1998; Klug et al. 2000; Syka et al. 2000). This range is broader than observed in lower auditory brainstem nuclei (Halpea et al. 1994; Klug et al. 2000). Several functions have been suggested for this wider range of response latencies in the IC. Long latencies may be essential for creating delay lines used in coincidence detectors that encode such sound attributes as loca- 
tion, pitch, and duration (e.g., Rees and Moller 1983; Yin et al. 1985; Langner and Schreiner 1988; Pollak 1988; Carney and Yin 1989; Casseday et al. 1994; Fuzessery 1997). In bats, for example, proposed coincidence mechanisms that create neuronal selectivity for pulse-echo delays used in determining target distance may require that the excitation from the emitted pulse be delayed up to $20 \mathrm{~ms}$ so that it arrives simultaneously with the excitation generated by the returning echo (Feng et al. 1978; Sullivan 1982; Dear and Suga 1995; Mittmann and Wenstrup 1995; Saitoh and Suga 1996; Ferragamo et al. 1998; Portfors and Wenstrup 1999). Neurons with long latencies are needed to process such information. These forms of coincidence detection appear first at the IC level (Halpea et al. 1994; Mittmann and Wenstrup 1995; Casseday and Covey 1995; Yan and Suga 1996), suggesting that the increase in response latencies observed in the IC may support their creation. A wide range of latencies and a slowing of responses may also be necessary for the coordination of sensorimotor interactions (Casseday and Covey 1995). In vocalization behavior, for example, bats must rapidly adjust their biosonar emissions on the basis of information in prior echoes (Henson et al. 1982; Schuller et al. 1975). Finally, if neurons responding to the same sounds have markedly different response latencies, those with longer latencies may create a neural "trace" of previous input that allows comparisons between sequential input. In bats, this would be particularly useful for extracting information across two or more echoes (Dear et al. 1993).

Several mechanisms may contribute to the range of response latencies reported in the IC. These include differential delays across frequency due to cochlear mechanics, axonal conduction times, the imposition of additional synapses, synaptic integration times, and inhibitory inputs that delay excitation. It is difficult to account for $10-15 \mathrm{~ms}$ increases in response latencies in the IC through the first three mechanisms. Several studies have suggested that longer latencies in IC neurons are created in part by fast inhibitory inputs that precede excitation (Park and Pollak 1993; Casseday and Covey 1995; Covey et al. 1996; Saitoh and Suga 1995). Intracellular and whole-cell patch-clamp studies have demonstrated that neurons with short-latency IPSPs that precede excitation are common in the IC (Smith 1992; Covey et al. 1996; Wagner 1996; Kuwada et al. 1997; Li et al. 1999). Blocking GABAa and glycine receptors can also shorten response latencies in the IC, presumably through the elimination of these early IPSPs (Smith 1992). In the mustached bat IC, blocking inhibition can reduce response latencies as much as $20 \mathrm{~ms}$ (Park and Pollak 1993), but these large changes are due in part to the inclusion of neurons that normally respond at the end of a stimulus and which are converted to "on" responders following disinhibition. Much more modest changes in response latencies $(<4$ $\mathrm{ms}$ ) have been reported in similar studies in the guinea pig (Le Beau et al. 1996) and the big brown bat (Johnson 1993; Casseday and Covey 1995; Lu et al. 1997).

The present report combines the results of two parallel, independent studies that examined the role of inhibition on response latencies by the iontophoretic application of GABAa and glycine receptor blockers to single neurons in the ICC (central nucleus of the inferior colliculus) in two species of bats, the pallid bat (Antrozous pallidus) and the mustached bat (Pteronotus parnellii). To maximize the possibility of finding significant effects on response latency, different strategies were adopted in the two species to exploit differences in the functional specializations of their auditory systems. The pallid bat is a gleaner that uses echolocation for general orientation but relies on low-frequency passive sound localization to detect terrestrial prey (Brown 1976; Fuzessery et al. 1993). Neurons were sampled throughout its broad audible range, with a focus on neurons with longer response latencies, the assumption being that early inhibitory input is most likely to play a role in shaping their latencies. The mustached bat is a specialized echolocator with pulse-echo delay-sensitive neurons present at the level of the ICC (Mittmann and Wenstrup 1995; Yan and Suga 1996). This sensitivity is created through inhibitory and facilitatory interactions generated by different frequency components in the pulse and echo presented at specific delays (Wenstrup and Leroy 2001). The focus in the mustached bat was to survey high-frequency, delay-sensitive neurons with the expectation that the elimination of inhibitory input might result in large changes in response latency. Despite the different approaches in different species, the results are similar.

\section{MATERIALS AND METHODS}

\section{Surgical procedures}

Bats were prepared for surgery by first anesthetizing them by methoxyflurane (Metofane) inhalation, followed by an intraperitoneal injection of sodium pentobarbital (Nembutal, $30 \mu \mathrm{g} / \mathrm{g}$ and $5 \mu \mathrm{g} / \mathrm{g}$ body weight in the pallid bat and mustached bat, respectively) and acepromazine (2 $\mu \mathrm{g} / \mathrm{g}$ body weight). To expose the IC, the head was held in a bite bar, a midline incision made in the scalp, and the muscles over the dorsal surface of the skull were reflected. In preparation for securing an aluminum head pin to the skull, the skull over the neocortex was scraped clean, a layer of glass microbeads and cyanoacrylate 
cement was placed on the skull over the neocortex, followed by a layer of dental cement. Using skull and brain surface landmarks (the skulls in these bats are semitransparent), a small hole $(0.5 \mathrm{~mm}$ diameter $)$ was made over the center of the IC with a scalpel blade. Exposed muscle was covered with Vaseline, and the exposed area of the brain covered with paraffin oil to prevent desiccation. The bat was then placed in a restraining device holding the body. A head pin, inserted through a crossbar over the bat's head, was cemented with dental cement to the previously prepared region of the skull. The pin served to hold the bat's head secure during the recording session.

\section{Recording procedures}

A full account of the procedures used in these studies can be found in Fuzessery and Hall (1999) and Wenstrup and Leroy (2001). Briefly, experiments were conducted in a heated, sound-proofed chamber lined with anechoic foam. During the course of experiments, additional sodium pentobarbital $(50 \%$ of presurgical dose) was administered intraperitoneally to maintain light anesthesia in the pallid bats; mustached bats were awake during experiments. It is important to note that despite the fact that pallid bats were lightly anesthetized with sodium pentobarbital, which can potentiate GABAergic action, the results obtained in the pallid and mustached bats were very similar, suggesting that anesthesia did not have a significant effect on action of the receptor blockers used in this study. Had a potentiation of inhibition influenced results, we would have expected greater changes in response latency following receptor blockade in the pallid bat, but this was not the case.

Piggyback multibarrel microelectrodes (Havey and Caspary 1980) were used for single-unit recording and the iontophoresis of the GABAa receptor blocker bicuculline and of the glycine receptor blocker strychnine. A five-barrel, H-configuration micropipette was pulled and the tip broken back to a diameter of 10-15 $\mu \mathrm{m}$. The single-barrel micropipette, used to record single-unit activity, was positioned at an angle of approximately $20^{\circ}$ to the five-barrel pipette and glued in place with cyanoacrylate so that the single-barrel tip extended $5-10 \mu \mathrm{m}$ beyond the tip of the multibarrel pipette. The central barrel of the multibarrel pipette was filled with $1 \mathrm{M} \mathrm{NaCl}(\mathrm{pH} 7.4)$ and used to balance iontophoretic currents. Each of the remaining barrels was filled with bicuculline methiodide (10 mM, pH 3.0) and strychnine hydrochloride (10 mM, pH 3.5). The recording barrel was connected to a Dagan AC amplifier (model 2400) via a chlorided silver wire. Drug and balancing barrels were connected via chlorided silver wire to a Medical
Systems Neurophore BH-2 (pallid bat) or Dagan Model 6400 (mustached bat) used to generate and monitor iontophoretic currents. Positive currents of 4-60 nA were used for iontophoresis. Current was gradually increased until the response of a neuron was obviously altered by the receptor blockade. There was typically an obvious increase in response magnitude and/or duration of the response, but other criteria, such as a loss of selectivity for stimulus duration in the pallid bat or a loss of tone-combination sensitivity in the mustached bat, were also used to determine that the iontophoresed drugs were having an effect. One or more of these effects were observed in all neurons tested before the changes in response latency were calculated. Electrodes were advanced into the IC with a Kopf hydraulic microdrive controlled from outside of the sound-proofed chamber. Recording sites in the three dimensions of the IC were determined by dorsal skull and brain surface landmarks over the ICC and by the best frequencies of neurons within the tonotopic map of the ICC.

\section{Data collection}

In the pallid bat study, sounds were presented at 400 $\mathrm{ms}$ intervals, with the cosine-squared rise/fall time of the sound envelope held constant at a short $0.5 \mathrm{~ms}$ to eliminate any effects that the envelope shape might have on response latency (e.g., Heil and Neubauer 2001). Most neurons were tested with tones at their best frequency $(\mathrm{BF})$, though a small percentage responded best to noise and were tested with that stimulus. For 241 neurons tested, first-spike response latencies were measured over a 10-50 dB range of intensity levels to determine the effect of intensity level on latency. Response latencies were also tested over a range of stimulus durations because many neurons are selective for short durations (Fuzessery and Hall 1999), and duration can have a marked effect on first-spike latency. The response latency of a neuron was quantified as the shortest first-spike latency observed after these stimulus manipulations. For the 38 neurons that received an iontophoretic application of inhibitory receptor blockers, these measures were repeated during application and the change in latency compared using the stimulus evoking the shortest latency in the predrug condition. Average first-spike response latencies were calculated from responses to 30 stimulus presentations using poststimulus time histogram bins with a resolution of $100 \mu \mathrm{s}$.

The procedures used in the mustached bat study were the same, except for the following: All 52 neurons tested were combination-sensitive, as described by Portfors and Wenstrup (1999). In 21 neurons, response latencies were measured over the neuron's 

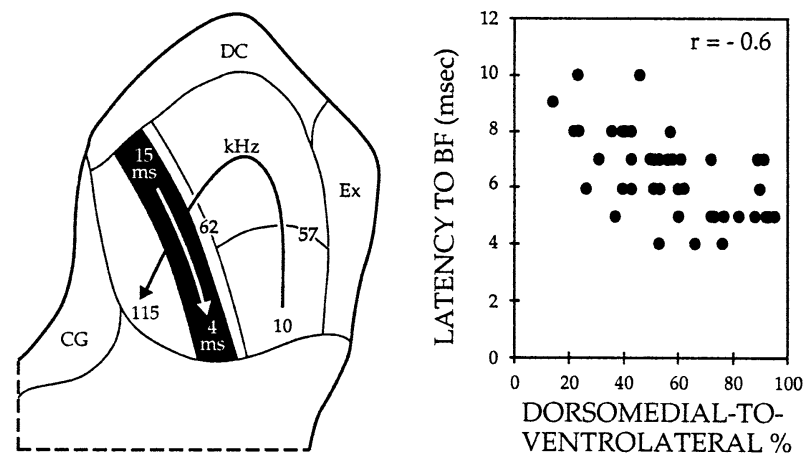

FIG. 1. Left: Transverse section of the mustached bat IC, showing the unusual tonotopy of the central nucleus and the change in response latency within the $60 \mathrm{kHz}$ region(black). CG, central gray; DC dorsal cortex; Ex, external nucleus. Right: The systematic change in response latency along the dorsomedial to ventrolateral axis (from Portfors and Wenstrup 2001).

dynamic intensity range, and its latency quantified as the shortest latency observed over this range, as in the pallid bat. In the remaining 31 neurons, latencies were obtained at $10 \mathrm{~dB}$ above their excitatory thresholds in the predrug condition and then tested during drug application at the same absolute intensity. First-spike latencies were calculated from responses to 32 stimulus presentations.

\section{RESULTS}

Distribution and range of response latencies in the pallid bat

The range and anatomical distribution of response latencies have been previously described for the mustached bat (Park and Pollak 1993; Hattori and Suga 1997; Portfors and Wenstrup 2001). Response latencies decrease with depth in the hypertrophied 60 $\mathrm{kHz}$ region and in regions representing lower and higher frequencies. There is also an increase in response latency along the ventrolateral-dorsomedial axis. The tonotopic organization of the mustached bat IC and latency axis for the $60 \mathrm{kHz}$ is summarized in Figure 1 (from Portfors and Wenstrup 2001).

The distribution of response latencies in the pallid bat IC has not been previously described and is summarized here. To estimate the time required for ascending brainstem input to reach the IC, compound potentials were recorded with low-impedance metal electrodes. In response to tone bursts, a single compound potential was recorded that preceded the multiunit activity of IC neurons. This potential presumably represents the synchronized arrival of lateral lemniscal afferent fibers. The latencies of the peaks of these compound potentials, recorded along the extent of the dorsoventral axis of the IC, ranged from 4 to $6 \mathrm{~ms}$. This method provides an estimate of the minimum possible response latencies of IC neurons. This assumption is supported by the finding that no IC neurons had latencies shorter than $5 \mathrm{~ms}$.

The pallid bat IC has unusual features that require explanation before describing the topographic distribution of response latencies. It has an orderly tonotopy, but the ICC (central nucleus of the IC) is hypertrophied, extending laterally into the region occupied by the external nucleus of the IC in other species (Fig. 2). This region, termed the lateral IC (Fuzessery and Hall 1999), is a lateral extension of isofrequency layers representing the lower half (5-30 $\mathrm{kHz}$ ) of the bat's audible range. These frequencies are largely below the spectrum of the bat's echolocation pulse $(30-80 \mathrm{kHz})$ and serve passive listening (Fuzessery 1997). Isofrequency layers tuned to higher frequencies $(>40 \mathrm{kHz})$ are located more medially and do not extend to the lateral wall of the IC (Fig. 2).

Neurons in the lateral IC have response latencies as short as $5 \mathrm{~ms}$, the shortest recorded in the IC (Fig. 2 ). Based on the above estimate of the arrival times of afferent input, these response latencies probably represent the shortest possible response times in the pallid bat ICC. In contrast, few neurons tuned to the same low-frequency range in the medial IC had response latencies of $<10 \mathrm{~ms}$.

Lateral IC neurons had a response latency range of $5-27 \mathrm{~ms} \quad(n=35$, mean $=11.6 \mathrm{~ms})$. More medial neurons had a range of $7-50 \mathrm{~ms}(n=156$, mean $=15.7$ $\mathrm{ms})$. The widest range of latencies was observed in neurons tuned to $<30 \mathrm{kHz}$ (Fig. 2). In both the lateral and medial regions, the range of response latencies narrowed with increasing best frequency, and average response latencies decreased. Both frequency tuning and anatomical location within the IC are correlated with response latency. Latencies decreased with increasing best frequency along the dorsoventral axis and increased in a lateral to medial direction. As illustrated in three electrode penetrations in one IC (Fig. 3), response latencies tended to decrease with increasing best frequencies. However, within the same range of best frequencies, for example, comparing response latencies of neurons tuned near $20 \mathrm{kHz}$ in penetrations 1 and 3 in Figure 3, the latencies of neurons in the medial IC could be more than $8 \mathrm{~ms}$ longer than those in the lateral IC. In the larger population of neurons from the medial IC shown in Figure 2 , neurons with similar best frequencies, and hence recorded at similar dorsoventral positions, could have response latencies that differed by more than $20 \mathrm{~ms}$ (e.g., at $20 \mathrm{kHz}$ best frequency in Fig. 2).

\section{Effect of blocking inhibition}

In the pallid bat, neurons with low best frequencies in the medial region, where latencies were longest (Figs. 

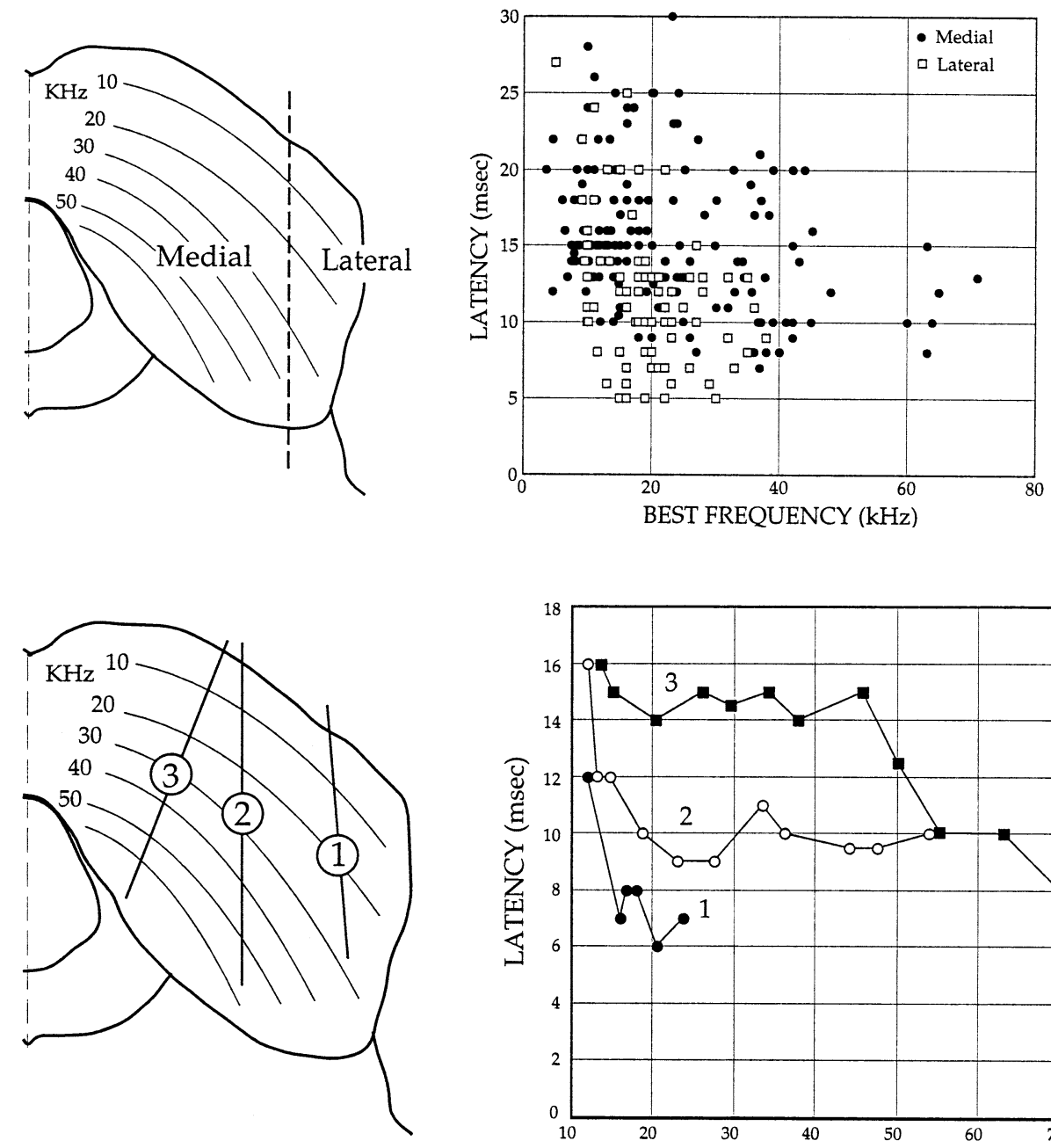

FIG. 2. Left: Transverse section of the pallid bat IC showing isofrequency contours and functionally defined medial and lateral regions (vertical dashed line). Right: The distribution of response latencies in the pallid bat IC as a function of best frequency and location in the medial (filled circles) and lateral (open squares) regions ofthe IC. Neurons in the lateral IC are tuned to $<40 \mathrm{kHz}$. Therefore, the distribution of best frequencies is more limited than that of the medial IC. Two neurons from the medial IC with long latencies of 35 and $50 \mathrm{~ms}$ are not shown.
FIG. 3. Left: Three electrode penetrations through the pallid bat IC, varying in lateromedial location. Right: The latencies and best frequencies of neurons recorded in the three penetrations showing that latency varied as a function of best frequency and location.
2 and 3), received the greatest attention, the assumption being that if inhibition does influence response latency, it should be most pronounced in neurons with longer latencies. Thirty-eight neurons were tested before and during the application of bicuculline and/or strychnine. Twenty-six were tested with bicuculline, 12 with strychnine, and 4 were tested first with bicuculline and then strychnine. Predrug latencies ranged from 9.6 to $25.7 \mathrm{~ms}$ (Fig. 4). Best frequencies ranged from 4.6 to $49 \mathrm{kHz}$, but the majority had best frequencies of $\leq 20 \mathrm{kHz}$ (Fig. 4). The relationship between response latency and best frequency was similar to that of the larger population described above (Fig. 2), with the latency range broadest at low best frequencies, narrowing with increasing best frequency, and with similar minimum response latencies across the best frequency range.

In the mustached bat, of 52 neurons tested, 25 were tested with bicuculline, 27 with strychnine, and 10 with bicuculline followed by strychnine. The great majority of these neurons were tuned to the higher harmonics of the echolocation pulse and had best frequencies of $>50 \mathrm{kHz}$ (Fig. 4). Only one had a lower best frequency of $25.4 \mathrm{kHz}$. All neurons were combination-sensitive, as described in Portfors and Wenstrup (1999). Their predrug response latencies ranged from 4.0 to $17.2 \mathrm{~ms}$ (Fig. 4), a range which is similar to those reported in previous studies of neurons tuned to the higher harmonics of the echolocation pulse (Hattori and Suga 1997; Portfors and Wenstrup 2001), but which does not include the much longer latencies (up to $45 \mathrm{~ms}$ ) reported in the hypertrophied $60 \mathrm{kHz}$ region of the mustached bat inferior colliculus (Park and Pollak 1993).

In all 38 neurons tested in the pallid bat, and in 21 of the 52 neurons tested in the mustached bat, response latencies before and during disinhibition were measured over their dynamic intensity range because intensity level can have a large effect on latency (e.g., Irvine and Gago 1990; Klug et al. 2000), with latency typically decreasing with increasing intensity level (Figs. 5 and 6, right columns). The change in latency ascribed to disinhibition was measured at the intensity level that produced the shortest latency in 


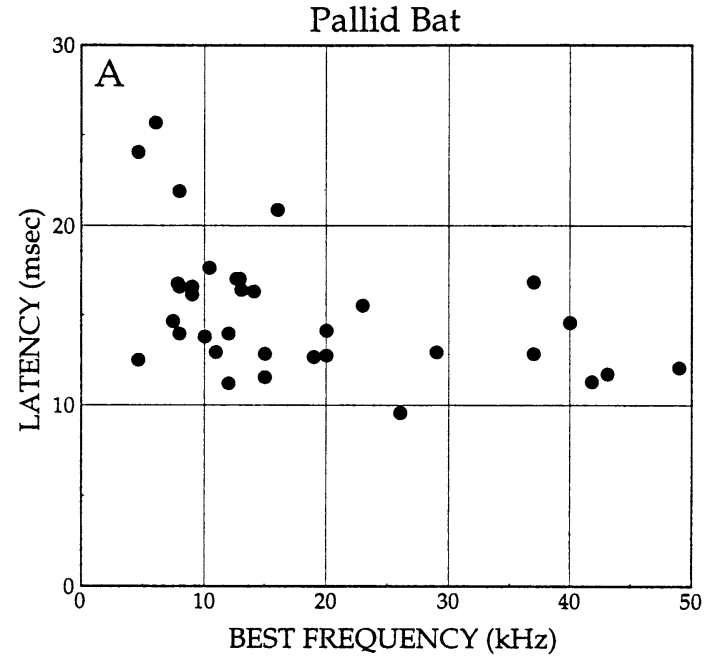

FIG. 4. The distribution of normal response latencies of neurons in the ICs of the pallid bat (left) and mustached bat (right) prior to blockade of their inhibitory inputs. For the mustached bat, neurons

the predrug condition. In neurons that had monotonic or plateaued intensity-rate functions under both conditions (Figs. 5 and 6, left columns), the intensity-latency functions tended to run parallel (e.g., Figs. 5E-H, 6G,H). Once latency changes plateaued at $10-30 \mathrm{~dB}$ above threshold, latency changes across intensity levels were similar, making the choice of the predrug latency comparator less critical. The measure was more complicated in neurons in which blocking inhibition not only increased response magnitude but also changed intensity-rate function configurations or increased dynamic intensity ranges (e.g., Figs. 5A-D, 6C-F). In these cases, it was judged appropriate to also measure response latencies at the shortest latency in the predrug condition. It should also be noted that the increases in response magnitude and changes in intensity-rate functions provide assurance that these neurons were indeed being influenced by the application of receptor blockers.

In the pallid bat, maximum changes in response latencies during blockade of inhibition ranged from a $3.8 \mathrm{~ms}$ decrease to a $1.7 \mathrm{~ms}$ increase (Fig. 7C), but the great majority of neurons showed changes of $<1 \mathrm{~ms}$. Blocking GABAa receptors had a greater effect on decreasing response latencies than did blocking glycine receptors. Increased latencies of $>0.5 \mathrm{~ms}$ were observed only when glycine receptors were blocked. Similar changes in latency were observed across best frequencies (Fig. 7C) and also across the range of predrug latencies (Fig. 7A). The average latency change when blocking GABAa receptors was $-0.7 \mathrm{~ms}$ (range $=-3.8$ to $+0.2 \mathrm{~ms}, \mathrm{SD}=1.0 \mathrm{~ms}$ ). The average change when blocking glycine receptors was $-0.1 \mathrm{~ms}$ $($ range $=-1.3$ to $+1.7 \mathrm{~ms}, \mathrm{SD}=0.8 \mathrm{~ms})$.

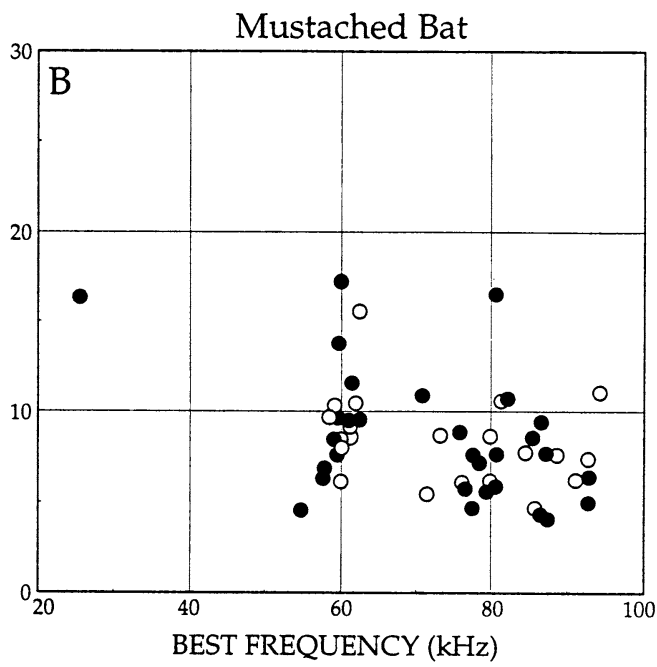

in which response latencies were tested over the dynamic intensity range of the neuron are indicated by open circles. Those tested at $10 \mathrm{~dB}$ above threshold are indicated by filled circles.

In the mustached bat, changes in response latency ranged from a decrease of $10.3 \mathrm{~ms}$ to an increase of 1.4 $\mathrm{ms}$, but, as in the pallid bat, the majority showed changes of $<1 \mathrm{~ms}$ (Fig. 7D). There was no significant difference in the effects of bicuculline and strychnine. The average change when blocking GABAa receptors was $-0.9 \mathrm{~ms}$ (range $=-10.3$ to $+1.4 \mathrm{~ms}, \mathrm{SD}=2.2 \mathrm{~ms}$ ). When glycine receptors were blocked, the average change was $-0.5 \mathrm{~ms}$ (range $=-3.6$ to $+1.0 \mathrm{~ms}, \mathrm{SD}=$ $-1.0 \mathrm{~ms})$. As in the pallid bat, similar changes were observed across the range of best frequencies (Fig. 7D), but the mustached bat differed in that neurons with longest latencies tended to show larger changes in response latency during disinhibition (Fig. 7B).

As noted above, 21 of the 52 neurons in the mustached bat were tested over their dynamic intensity range, while the remaining 31 were tested only at 10 $\mathrm{dB}$ above their intensity threshold (Fig. 7D). Their intensity threshold was defined in the predrug condition, and their response latency was measured at the same absolute intensity level during drug application. Despite the differences in how these two neuronal populations were tested, there was no significant difference in latency changes in these two populations (Fig. 7D; not significantly different in a $t$-test at $p>0.65)$.

Representative changes in temporal response properties are shown in Figure 8 . In the pallid bat (Fig. 8, left column), the neuron in Figure 8A,B showed an average $0.8 \mathrm{~ms}$ decrease in latency in response to bicuculline. In the predrug condition, the neuron fired one spike. During bicuculline application, it fired two spikes in this intial burst, the first spike occurring $0.5-12 \mathrm{~ms}$ earlier than in the predrug condition, followed by a third spike of irregular tim- 

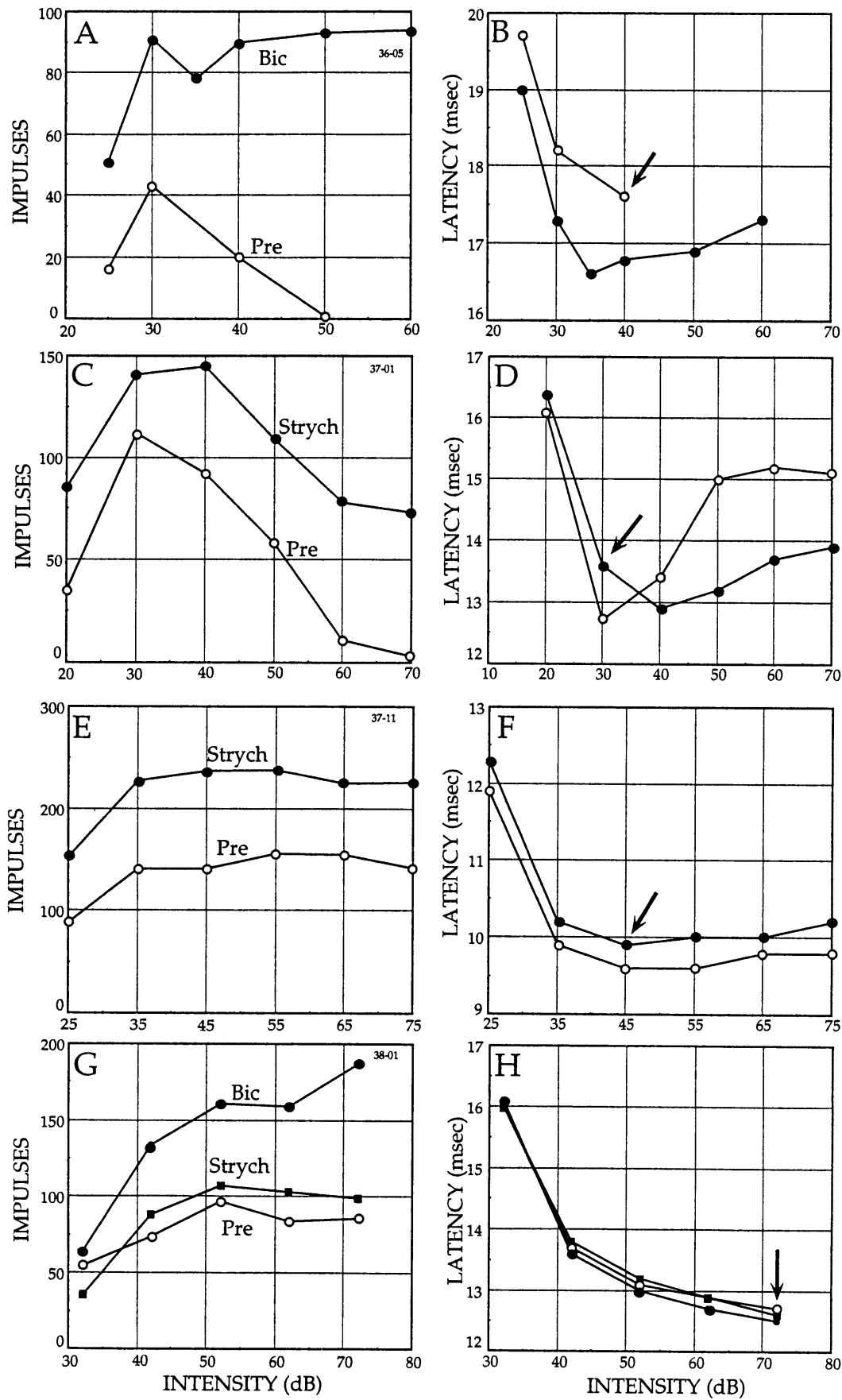

FIG. 5. Four neurons from the pallid bat IC showing the effect of blocking GABAergic input with bicuculline (Bic) or glycinergic input with strychnine (Strych) relative to the predrug (Pre) condition. Left column shows the effect of disinhibition on intensity-rate functions. Right column shows the effect of response latency as a function of intensity level. The arrows in the right columnindicate the intensity level at which changes in response latency were measured. The same symbols are used in the pairs of figures in the left and right columns to indicate drug and predrug conditions. ing. Bicuculline appeared to release this neuron from inhibition that occurred both before and after the normal excitation.

Disinhibition by bicuculline had similar but greater effects on the neuron in Figure 8C,D. It sometimes fired a first spike approximately $2 \mathrm{~ms}$ earlier than in the predrug condition, but because this early response was inconsistent, its average latency was longer and there was only a $0.8 \mathrm{~ms}$ difference in mean latencies under the two conditions. The timing of the second peak of first-spike timing during bicuculline application is similar to that of the first peak in the predrug condition. This result suggests that bicuculline blocked an early GABAergic inhibition that retarded the response latency of this neuron. As in the previous neuron (Fig. 8A,B), bicuculline also removed a late inhibition and greatly increased the response duration.

The neuron in Figure $8 \mathrm{E}-\mathrm{G}$ was sequentially exposed to bicuculline and strychnine. Bicuculline increased the duration and magnitude of its response and decreased response latency an average of $1.0 \mathrm{~ms}$ (Fig. 8G). In contrast, strychnine increased its latency by an average of $1.7 \mathrm{~ms}$ (Fig. $8 \mathrm{~F}$ ). As was typically the 

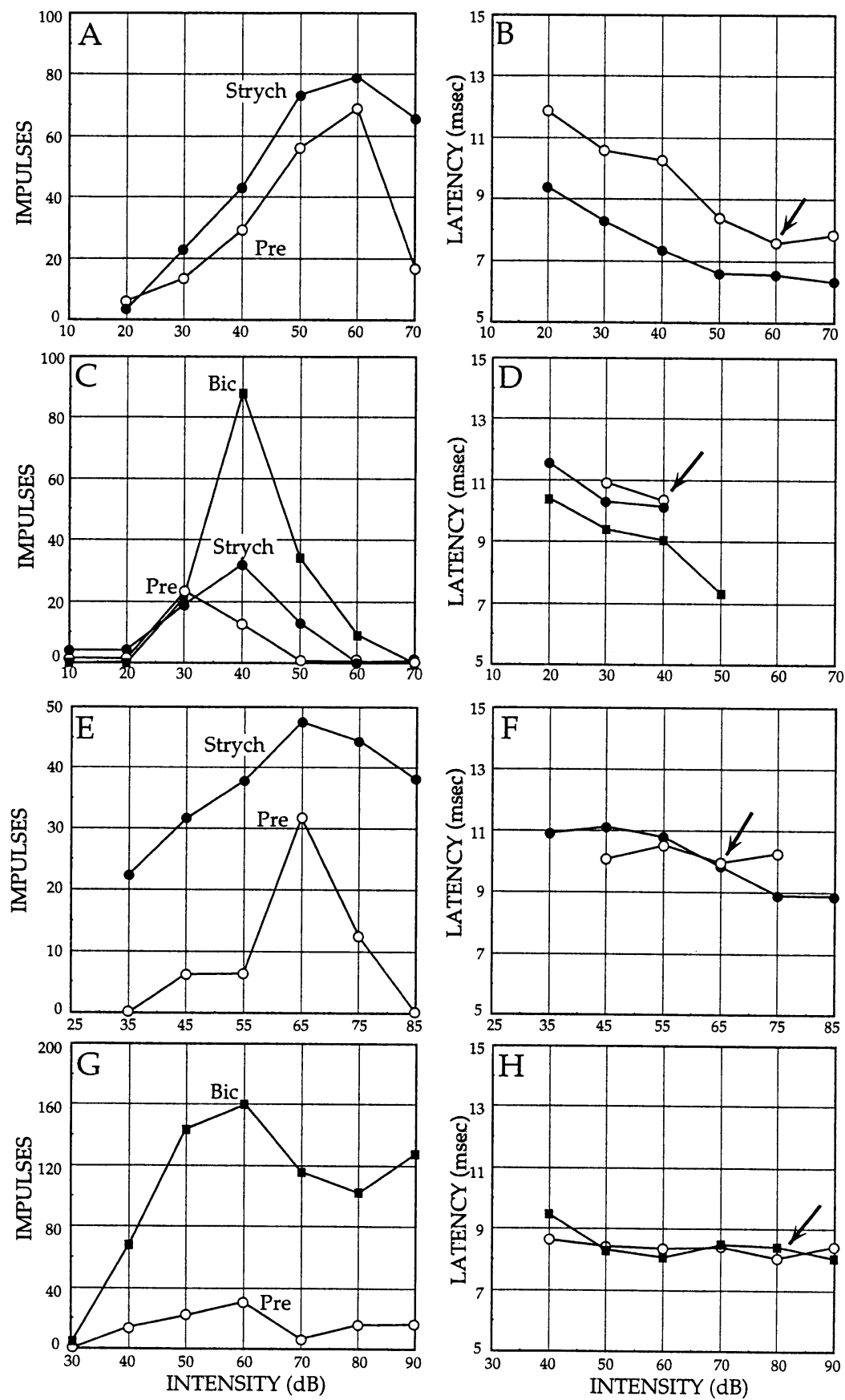

FIG. 6. Four neurons from the mustached bat IC. The same convention as in Fig. 4 was used to show the effects of bicuculline and/or strychnine on intensity-rate functions and intensity-latency functions. case, bicuculline increased response magnitude more than strychnine.

Similar changes in poststimulus time histograms were seen in the mustached bat (Fig. 8, right column). Figure $8 \mathrm{H}, \mathrm{I}$ shows the largest latency change observed after application of an antagonist in this study, $10.3 \mathrm{~ms}$. In control tests, the unit responded on average with one spike to the best frequency stimulus. The first spike occurred as little as $11 \mathrm{~ms}$ after stimulus onset, but, because of the high variability $(\mathrm{SD}=6.0 \mathrm{~ms})$, the median latency was $17.5 \mathrm{~ms}$. With bicuculline, the response rate increased by a factor of
5. The earliest latencies decreased to $7 \mathrm{~ms}$ and the distribution of latencies was much tighter $(\mathrm{SD}=1.1$ $\mathrm{ms}$, median latency $=7.2 \mathrm{~ms}$ ). Thus, bicuculline revealed two large effects of GABAa inhibition on latency: a decrease in the first-spike timing and an increase in the consistency of the first spike. Such large combined effects were not seen in other units.

Figure 8J,K shows a very small effect of bicuculline on latency despite a major effect on response magnitude. The unit (also shown in Fig. 6G,H) responded weakly in the control condition, but the latency of response varied little $(\mathrm{SD}=0.8 \mathrm{~ms}$, median laten- 
Pallid Bat
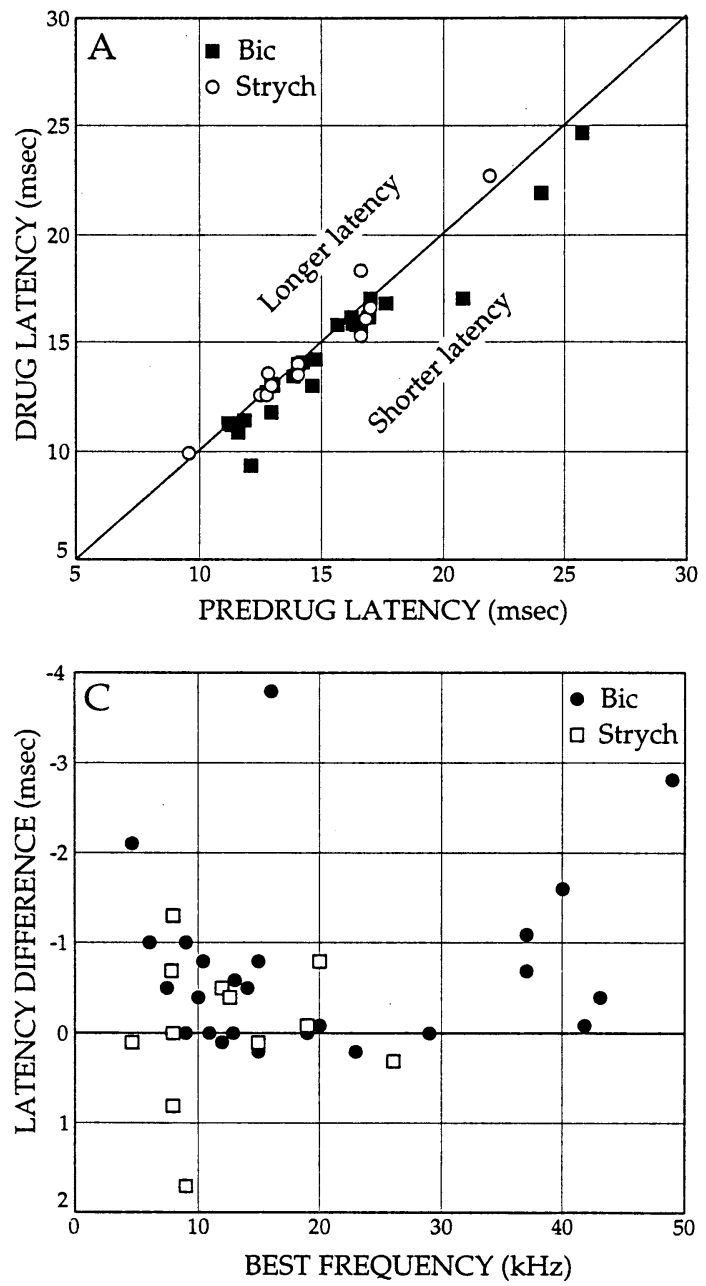

FIG. 7. Top row: The distribution of response latencies under predrug and drug conditions for the pallid bat (left column) and mustached bat (right column) as a function of predrug response latency. Points residing on the diagonal line would indicate no difference. Points below the line indicate that disinhibition shortened latencies, while points above the line indicate an increase in latency. Note that in the mustached bat, disinhibition produced a greater shortening of

cy $=8.4 \mathrm{~ms}$ ). With bicuculline, the response rate increased by a factor of 6 but neither the latency nor its variability changed much $(\mathrm{SD}=0.6 \mathrm{~ms}$, median latency $=8.7 \mathrm{~ms}$ ).

The unit in Figure 8L-N showed only small effects of both bicuculline and strychnine on response latency (see also Fig. 6C,D). The unit's control response was weak, partly a result of inhibition occurring at higher stimulus levels. Median first spike latency was $10.7 \mathrm{~ms}$, with little variation $(\mathrm{SD}=1.2$ $\mathrm{ms})$. With strychnine, the response level roughly doubled, but first-spike latency remained nearly the same with little variation $(\mathrm{SD}=1.3 \mathrm{~ms}$, median latency $=10.6 \mathrm{~ms}$ ). With bicuculline, the response rate increased further, but the median first-spike latency decreased to only $9.8 \mathrm{~ms}(\mathrm{SD}=1.5 \mathrm{~ms})$.
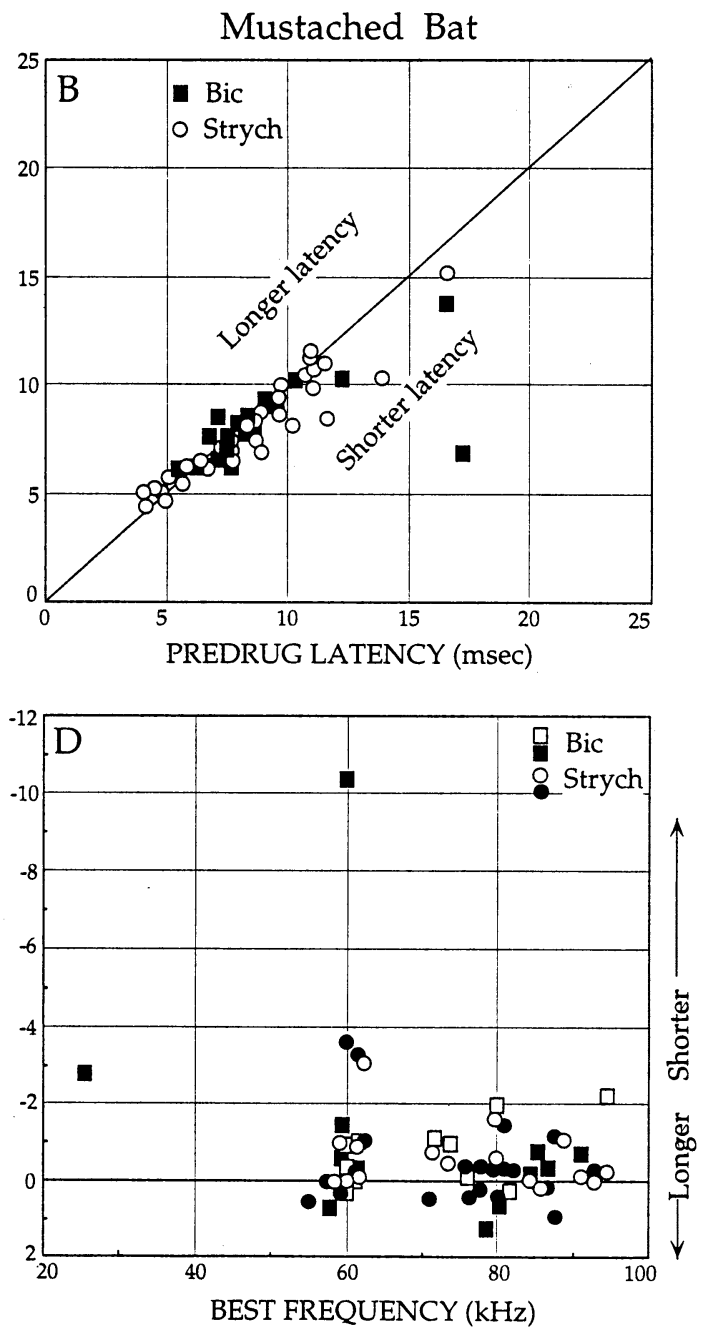

response latencies in neurons withlonger latencies. Bottom row: Changes in response latency during disinhibition as a function of best frequency. Negative latency differences indicate a shortening of response latency. For the mustached bat $(\mathbf{D})$, the open symbols indicate results from neurons tested over their dynamic intensity range; filled symbols indicate those tested only at $10 \mathrm{~dB}$ above their intensity thresholds.

\section{DISCUSSION}

This study focused on the role of GABA and glycinergic input in regulating the first-spike response latencies of IC neurons. In both species tested, inhibition had pronounced effects on the duration and magnitude of responses, as well as on the shapes of intensity-rate functions, but only modest effects on response latency. The majority of neurons showed latency shifts of $<1 \mathrm{~ms}$, despite the fact that, in the pallid bat, all neurons tested had normal (predrug) response latencies that were $5-20 \mathrm{~ms}$ longer than the shortest latency $(5 \mathrm{~ms}$ ) observed in the IC. Previous studies of other species report similar results. In the big brown bat (Johnson 1993; Lu et al. 1997) and the guinea pig (Le Beau et al. 1996), few neurons showed 

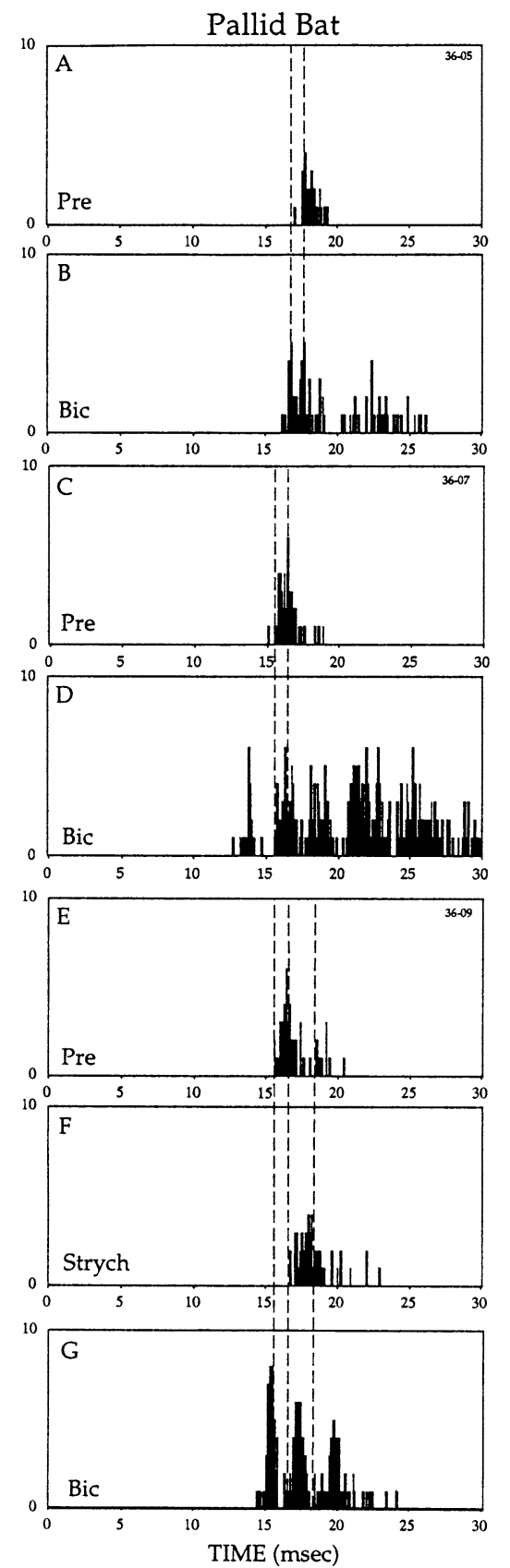
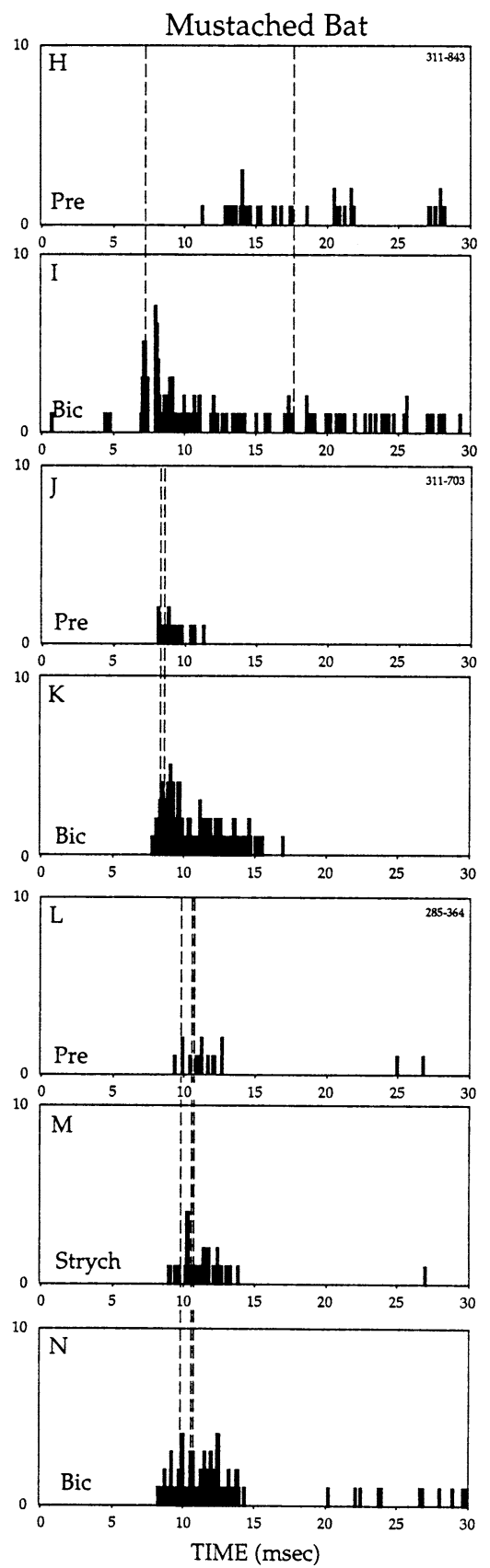

FIG. 8. Representative examples of the poststimulus time histograms of neurons from the pallid bat (left column) and mustached bat (right column) before and during disinhibition. The vertical dashed lines show mean first-spike latencies in the pallid bat and median first-spike latencies in the mustached bat for different conditions (see text). All neurons were tested with stimulus parameters that evoked the greatest responses and shortest response latencies. For the pallid bat (left column) all were tested with best frequency tones at 15-20 dB above response threshold. Since two of these neurons (A, B and $\mathbf{E}-\mathbf{G})$ were duration selective, they were tested at their best durations of 5 and $1 \mathrm{~ms}$, respectively. The neuron in C, D was tested with a $10 \mathrm{~ms}$ duration tone. changes in response latency that were $\pm 4 \mathrm{~ms}$, despite large changes in other response properties. When larger changes $(>5 \mathrm{~ms}$ ) in response latency were observed in the guinea pig (Le Beau et al. 1996), they were specifically associated with neurons with sustained responses. Neurons eliciting phasic bursts at onset typically showed less change. Park and Pollak (1993) also noted the largest latency changes in neurons with sustained discharges and suggested that it was because GABAergic disinhibition allows their first spikes to occur in a tighter temporal register, thereby decreasing their average response latencies. This would suggest that inhibition decreases the overall responsiveness of these tonic responders but does not necessarily determine first-spike latency.

In contrast to these modest effects, Park and Pollak (1993) reported that $17 \%$ of neurons in the hypertrophied $60 \mathrm{kHz}$ representation of mustached bat IC showed decreases ranging from 5 to $25 \mathrm{~ms}$. Neurons with the largest decreases in latency were OFF responders (neurons that responded only at the end of a stimulus) that were converted to $\mathrm{ON}$ responders when disinhibited. Such neurons can be discounted from the present discussion since their response latencies are dependent on stimulus duration, and latency changes observed following disinhibition will 
also depend upon stimulus duration. However, this cannot account for all of the large decreases observed in the mustached bat. A trend noted by Park and Pollak (1993) is that neurons in the dorsal part of the $60 \mathrm{kHz}$ representation in the IC had the longest latencies (see also Hattori and Suga 1997), and this population showed the greatest effect of disinhibition on response latency. Present results from neurons in the mustached bat's $60 \mathrm{kHz}$ representation show indications of a similar trend (Fig. 6B); the longest latency neurons tuned to $60 \mathrm{kHz}$ were the only ones to show latency decreases of $3 \mathrm{~ms}$ or more following removal of inhibition. If more $60 \mathrm{kHz}$ neurons with longer response latencies had been included, our results might be more similar to those of Park and Pollak. There was no evidence of this trend among neurons tuned in the $72-95 \mathrm{kHz}$ range in mustached bats, or in the pallid bat (Fig. 6A).

Based on their data, Park and Pollak (1993) proposed that GABAergic inhibition shapes latency maps throughout the tonotopically organized IC. They furthermore proposed that the organization of latency in the IC could provide delay lines necessary for the construction of coincidence detectors selective for pulse-echo delay (see also Saitoh and Suga 1995; Hattori and Suga 1997). Although the range of latencies in the $60 \mathrm{kHz}$ representation of the mustached bat IC is not unusual, nor is its organization of latency, the dependence of latency on inhibition is remarkable. This led to speculation that the dependence of latency on inhibition is a specialized feature used by the mustached bat for the construction of coincidence detectors to analyze sonar echoes (Le Beau et al. 1996). However, results of several recent studies show that (1) coincidence detectors are created in the IC, not in the medial geniculate body as these proposals require (Mittmann and Wenstrup 1995; Wenstrup and Leroy 2001); (2) latency maps in the IC have no apparent relationship with the delay tuning of coincidence detectors in the IC (Portfors and Wenstrup 1999, 2001; Wenstrup et al. 1999); and (3) among the delay-tuned neurons recorded from the mustached bat's IC in the present study (with BFs of 72-89 kHz), neither GABAergic nor glycinergic inhibition appears to contribute significantly to the latency of response to BF signals. More generally, the present results in bats, as in other mammals, show that GABAergic and glycinergic inhibitions do not contribute significantly to response latency in the great majority of the population of IC neurons.

\section{Mechanisms shaping response latency}

A shortening of response latency following the blockade of GABAa or glycine receptors, regardless of the magnitude of the effect, indicates that a short- latency inhibitory input, either preceding or coinciding with the arrival of excitatory input, is able to counter depolarization and delay spike generation (Park and Pollak 1993; Halpea et al. 1994; Saitoh and Suga 1995; Casseday and Covey 1995). Preceding IPSPs in the IC have been observed in whole-cell patch-clamp (Covey et al. 1996) and intracellular (Nelson and Erulkar 1963; Kuwada et al. 1997) recordings as well as intracellular brain slice recordings (Smith 1992; Wagner 1996; Li et al. 1999). These early IPSPs were observed even when a neuron was presented with its most excitatory stimulus (Casseday et al. 1994; Covey et al. 1996). In addition to influencing the onset of a response, inhibition also shapes its duration and offset, since blocking inhibition often converts neurons with phasic responses to tonic responders whose response durations last well beyond the stimulus duration (e.g., Fig. 8). This latter effect of disinhibition is typically more profound than the effect on first-spike latency.

In addition to decreasing response latency, blocking inhibitory receptors can also increase latency by up to $3 \mathrm{~ms}$. In the present study of the pallid bat, this occurred only when glycinergic input was blocked. In the mustached bat, this occurred following blockade of either glycinergic or GABAergic input. In both species, neurons were observed that showed decreased latencies in response to bicuculline and increased latencies in response to strychnine. Other studies (Park and Pollak 1993; Lu et al. 1997) have observed this when blocking GABAergic input. Why response latencies should increase during disinhibition is not clear. One possibility is that inhibitory inputs themselves are subject to inhibition, and a release from this inhibition would allow the inhibitory input to exert a greater inhibitory effect on the recorded neuron. If, for example, a local GABAergic inhibitory neuron close to the site of drug application received inhibition from a glycinergic input, then the application of strychnine would release the inhibitory neuron from inhibition, allowing it to exert a greater inhibitory effect on the recorded neuron and increase its response latency.

A second possible mechanism is that a rebound from inhibition may contribute to excitation in some neurons. Thus, elimination of an early inhibition could slow depolarization and increase latency. Increased excitation following hyperpolarization has been reported in vitro in the cochlear nucleus (Manis 1990) and in the dorsal nucleus of the lateral lemniscus (Wu and Kelly 1995), as well as in the IC (Smith 1992; Perruzi et al. 2000). In vivo, based on whole-cell patch-damp recordings, Casseday et al. (1994) have proposed that a rebound from early inhibition, coinciding with arrival of a late excitatory input, may underlie a selectivity for sound duration 
observed in the IC of the big brown bat. Additional evidence that inhibition may contribute to excitation in the inferior colliculus comes from a recent study of combination-sensitive neurons in the mustached bat (Wenstrup and Leroy 2001). The facilitated response produced by appropriate combinations of tones is eliminated by blocking inhibitory glycinergic input. This paradoxical result could be the result of blocking a postinhibitory rebound that contributes to excitation.

Inhibition can indeed influence the response latency of IC neurons, but, with the exception of longlatency neurons in the mustached bat (Park and Pollak 1993), the rather small effects observed in other species after blocking inhibition cannot account for the wide range of latencies present in the midbrain. Other mechanisms require greater attention. Wave propogation times along the cochlear basilar membrane can contribute to a short, frequency-dependent delay of around $1 \mathrm{~ms}$, with higher-frequency input arriving first (Rhode and Smith 1986). The influence of this cochlear delay on IC response latencies is most likely insignificant, particularly in the lateral region of the pallid bat IC, where neurons with low best frequencies have the shortest response latencies. While the range of latencies at low frequencies has been found to be broader, minimum latencies have been found to be largely independent of frequency tuning (e.g., Langner and Schriener 1988; Halpea et al. 1994).

Other factors that can influence response latency are axon length, conduction velocity, the number of synapses along an ascending pathway, and synaptic integration times. The contribution of each of these factors in IC response latencies is likely to vary across neurons. For example, studies that used electrical stimulation of the auditory nerve (Snyder et al. 1995) and dorsal cochlear nucleus (Semple and Aitkin 1980) in place of normal acoustic stimulation report a wide range of response latencies in the IC, leading to the conclusion that it is unlikely that axon lengths or the number of intercalated synapses could account for 10-20 ms differences in response latencies in the IC (Snyder et al. 1995). The increase in response latencies along the axis of the IC (e.g., Langner and Schriener 1988; Hattori and Suga 1997) is difficult to account for through additional travel time. This same gradient of response latencies was observed in the pallid bat IC, where more than $10 \mathrm{~ms}$ increases in latency occur over a separation of only $1.5 \mathrm{~mm}$.

Instead, much of the delay in response onset may reside in mechanisms that are intrinsic to the IC. Intracellular brain slice recordings of the ICC (Wagner 1996) report long response latencies (to $12 \mathrm{~ms}$ ), even when neurons are excited by electrical stimulation of the lateral lemniscus immediately ventral to the IC. In the cortices of the cat IC, regions that receive primarily intracollicular and neocortical inputs, excitatory postsynaptic potentials (EPSP) latencies of up to $11 \mathrm{~ms}$ were reported following stimulation of the commissure of the IC (Smith 1992). These long latencies following intracollicular electrical stimulation suggest that multisynaptic circuits and/or long synaptic integration times within the IC can potentially impose a delay in response that can be longer than the time required for the transmission of information from the cochlea to the IC. Indeed, Halpea et al. (1994) emphasized that, in the big brown bat, the minimum response latencies from the levels of the cochlear nucleus to the lateral lemniscal nuclei to the IC do not increase appreciably. Rather, it is the range of response latencies that increases dramatically as one ascends the auditory brainstem.

One mechanism that may contribute to the wide latency range is a difference in the types of excitatory and inhibitory receptor types across the IC and the manner in which they interact to control the timing of synaptic integration. AMPA and NMDA glutamate receptors, for example, are reported to activate fast and slow postsynaptic excitatory potentials, respectively (Yang et al. 1999; Kelly and Kidd 2000; Zhang and Kelly 2001). Similarly, GABAa and GABAb receptors appear to be responsible for inhibitory potentials with different time courses (Crunelli and Leresche 1991), and are reported to be differentially distributed across the IC (Vater et al. 1992; Fubara et al. 1996). Since the present study examined the roles of only fast inhibitory events mediated by GABAa and glycine receptors, the possible roles of other receptor types mediating slower, longer-lasting excitatory and inhibitory events in shaping response latency were not revealed.

In conclusion, this report does not question the importance of inhibition in regulating the timing of responses in the central auditory system. There is growing evidence that the timing of inhibitory and excitatory inputs plays an important role in shaping response selectivity for temporal features, such as duration, and for complex, behaviorally relevant sounds, particularly those with components that are delayed in time. Moreover, neurons with OFF responses due to inhibition imposed during the course of a sound will exhibit long delays that vary with sound duration. Rather, the present study examined IC neurons that responded at signal onset, some of which had long first-spike latencies (10-25 ms) that far exceeded the minimum time required for input to the IC. We asked whether these latencies could be further decreased by the blockade of inhibitory inputs when care had been taken to ensure that the sounds presented evoked responses at the shortest possible latencies prior to disinhibition by inhibitory 
transmitter blockers. Despite large effects on response magnitude and duration, the blockade of GABAa and glycine receptors typically produced small changes in response latency $(<1 \mathrm{~ms})$. This finding, coupled with those from most species, suggests that fast inhibitory pathways may not play a dominant role in creating the wide range of response latencies observed in the mammalian IC.

\section{ACKNOWLEDGMENTS}

We thank Carol Grose for technical assistance and Terri Zumsteg for editing the manuscript. We are grateful to the Wildlife Section of the Ministry of Agriculture, Land, and Marine Resources of Trinidad and Tobago for permission to export mustached bats. Research was supported by funds from the National Institutes of Health (RO1 DC00054 to ZMF and RO1 DC00937 to JJW) and the National Science Foundation (IBN-9828599 to ZMF).

\section{REFERENCES}

Brown P. Vocal communication in the pallid bat, Antrozous pallidus. Z. Tierpsychol. 41:34-54, 1976.

CARnEY LH, YIN TCT. Responses of low-frequency cells in the inferior colliculus to interaural time differences in clicks: excitatory and inhibitory components. J. Neurophysiol. 62:144-161, 1989.

Casseday JH, Ehrlich D, Covey E. Neural tuning for sound duration: role of inhibitory mechanisms in the inferior colliculus. Science 264:847-850, 1994.

Casseday JH, Covey E. Mechanisms for the analysis of auditory temporal patterns in the brainstem of echolocating bats. In: Covey E, Hawkings HL, Port RF (eds) Neural Representations of Temporal Patterns Plenum, New York, 1995, pp 25-52

Casseday JH, Covey E. A neuroethological theory of the operation of the inferior colliculus. Brain Behav. Evol. 47:311-336, 1996.

Covey E, Kauer JA, Casseday JH. Whole-cell patch-clamp recording reveals subthreshold sound-evoked postsynaptic currents in the inferior colliculus of awake bats. J. Neurosci. 16:3009-3018, 1996.

Crunelli V, Leresche N. A role for GABAb receptors in excitation and inhibition of thalamocortical cells. Trends Neurosci. 14:1621, 1991.

Dear SP, Simmons JA, Fritz J. A possible neuronal basis for the representation of acoustic scenes in auditory cortex of the big brown bat. Nature 364:620-623, 1993.

Dear SP, Suga N. Delay-tuned neurons in the midbrain of the big brown bat. J. Neurophysiol. 73:1084-1100, 1995.

Ehret G, Romand R. Development of tone response thresholds, latencies and tuning in the mouse inferior colliculus. Dev. Brain Res. 67:317-326, 1992.

Feng AS, Simmons JA, Kick SA. Echo detection and target-ranging neurons in the auditory system of the bat, Eptesicus fuscus. Science 202:645-648, 1978.

Ferragamo MJ, Haresign T, Simmons JA. Frequency tuning, latencies and responses to frequency-modulated sweeps in the inferior colliculus of the echolocating bat, Eptesicus fuscus. J. Comp. Physiol. 182:65-79, 1998.

Fitzpatrick DC, Kuwada S, Batra R, Trahiotis C. Neural responses to simple simulated echoes in the auditory brain stem of the unanesthetized rabbit. J. Neurophysiol. 74:2469-2486, 1995.
Fubara BM, Casseday JH, Covey E, Schartz-Bloom RD. Distribution of GABAA, GABAB and glycine receptors in the central auditory system of the big brown bat, Eptesicus fuscus. J. Comp. Neurol. 369:83-92, 1996.

Fuzessery ZM, Buttenhoff P, Andrews B, Kennedy JM. Passive sound localization of prey by the pallid bat (Antrozous p. pallidus). J. Comp. Physiol. 171:767-777, 1993.

FUZESSERY ZM. Acute sensitivity to interaural time differences in the inferior colliculus of a bat that relies of passive sound localization. Hear. Res. 109:46-62, 1997.

FuZESSERY ZM, Hall JC. Sound duration selectivity in the pallid bat inferior colliculus. Hear. Res. 137:137-154, 1999.

Halpea S, Covey E, Casseday JH. Frequency tuning and response latencies at three levels in the brainstem of the echolocating bat, Eptesicus fuscus. J. Comp. Physiol. 174:671-682, 1994.

Harrison RV, PALmer AR. Neurone response latency in the inferior colliculus in relation to the auditory brainstem responses (ABR) in the guinea pig. Scand. Audiol. 13:275-281, 1984.

Hattori T, Suga N. The inferior colliculus of the mustached bat has frequency-vs-latency coordinates. J. Comp. Physiol. 180:271284, 1997.

HaVEY DL, CASPARY DM. A simple technique for constructing "piggy-back" multibarrel microelectrodes. Electroencephalogr. Clin. Neurophysiol. 48:249-251, 1980.

Heil P, Neubauer H. Temporal integration of sound pressure determines thresholds of auditory-nerve fibers. J. Neurosci. 27:7404-7415, 2001.

Henson OW, Pollak GD, Kobler JB, Henson MM, Goldman LJ. Cochlear microphonic potentials elicited by biosonar in flying bats, Pteronotus p. parnelli. Hear. Res. 7:127-147, 1982.

IRvine DR, GAGO G. Binaural interactions in high-frequency neurons in inferior colliculus of the cat: effects of variations in sound pressure level on sensitivity to interaural intensity differences. J. Neurophysiol. 63:570-591, 1990.

Jen PH-S, Schlegel PA. Auditory physiological properties of the neurons in the inferior colliculus of the big brown bat, Eptesicus fuscus. J. Comp. Physiol. 147:351-363, 1982.

Johnson PA BR. GABAergic and glycinergic inhibition in the central nucleus of the inferior colliculus of the big brown bat. $\mathrm{PhD}$ thesis, Duke University, Durham, NC, 1993.

KeLLY JB, Kidd SA. NMDA and AMPA receptors in the dorsal nucleus of the lateral lemniscus shape binaural responses in rat inferior colliculus. J. Neurophysiol. 83:1403-1414, 2000.

Kitzes LM, Gibson MM, Rose JE, Hind JE. Initial discharge latency and threshold considerations for some neurons in the cochlear nucleus complex of the cat. J. Neurophysiol. 41:1165-1182, 1978.

Klug A, Khan A, Burger RM, Bauer Ee, Hurley LM, Yang L, Grothe B, Halvorsen MB, Park TJ. Latency as a function of intensity in auditory neurons: influences of central processing. Hear. Res. 148:107-123, 2000.

Kuwada S, Batra R, Yin TCT, Oliver DL, Haberly LB, Stanford TR. Intracellular recordings in response to monaural and binaural stimulation of neurons in the inferior colliculus of the cat. J. Neurosci. 17:7565-7581, 1997.

LANGner G, Schriener C, Merzenich MM. Covariance of latency and temporal resolution in the inferior colliculus of the cat. Hear. Res. 31:197-202, 1987.

Langner G, Schrienter C. Periodicity coding in the inferior colliculus of the cat. I. Neuronal mechanisms. J. Neurophysiol. 60:1799-1822, 1988.

Le Beau FEN, Rees A, Malmierca MS. Contribution of GABA- and glycine-mediated inhibition to the monaural temporal response properties of neurons in the inferior colliculus. J. Neurophysiol. 75:902-919, 1996. 
Li Y, Evans MS, Faingold CL. Synaptic response patterns of neurons in the cortex of rat inferior colliculus. Hear. Res. 137:1528, 1999.

Lu Y, Jen PH-S, Zheng Q-Y. GABAergic disinhibition changes the recovery cycle of bat inferior colliculus neurons. J. Comp. Physiol. 181:331-341, 1997.

MANIS PB. Membrane properties and discharge characteristics of guinea-pig dorsal cochlear nucleus neurons studies in vitro. $\mathrm{J}$. Neurosci. 10:2338-2351, 1990.

MitTmann DH, Wenstrup JJ. Combination-sensitive neurons in the inferior colliculus. Hear. Res. 90:185-191, 1995.

Nelson PG, ERulkar SD. Synaptic mechanisms of excitation and inhibition in the central auditory pathway. J. Neurophysiol. 26:908-923, 1963.

PARK TJ, PolLak GD. GABA shapes a topographic organization of response latency in the mustache bat's inferior colliculus. J. Neurosci. 13:5172-5187, 1993.

Peruzzi D, Sivaramakrishnan S, Oliver DL. Identification of cell types in brain slices of the inferior colliculus. Neuroscience 101:403-416, 2000.

Pollak GD. Time is traded for intensity in the bat's auditory system. Hear. Res. 36:107-124, 1988.

Portfors CV, Wenstrup JJ. Delay-tuned neurons in the inferior colliculus of the mustached bat: implications for analyses of target distance. J. Neurophysiol. 82:1326-1338, 1999.

Portfors CV, Wenstrup JJ. Topographical distribution of delaytuned responses in the mustached bat inferior colliculus. Hear. Res. 151:95-105, 2001.

Rees A, Moller AR. Responses of neurons in the inferior colliculus of the rat to AM and FM tones. Hear. Res. 10:301-330, 1983.

Rhode WS, Sмith PH. Physiological studies on neurons in the ventral cochlear nucleus of the cat. J. Neurophysiol. 56:287-307, 1986.

SAITOH I, Suga N. Long delay lines for ranging are created by inhibition in the inferior colliculus of the mustached bat. J. Neurophysiol. 74:1-11, 1995.

Schuller G, Beuter K, Rubsamen R. Dynamic properties of the compensation system for Doppler shifts in the bat, Rhinolophus ferrumequinum. J. Comp. Physiol. 97:113-125, 1975.

Semple MN, Aitkin LM. Physiology of pathway from dorsal cochlear nucleus to inferior colliculus revealed by electrical and auditory stimulation. Exp. Brain Res. 41:19-28, 1980.
SMITH PH. Anatomy and physiology of multipolar cells in the rat inferior collicular cortex using the in vitro brain slice technique. J. Neurosci. 12:3700-3715, 1992.

Snyder R, Leake P, Rebscher S, Beitel R. Temporal resolution of neurons in cat inferior colliculus to intracochlear electrical stimulation: Effects of neonatal deafening and chronic stimulation. J. Neurophysiol. 73:449-467, 1995.

Sullivan WE. Possible neuronal mechanisms of target distance coding in the auditory system of the echolocating bat Myotis lucifugus. J. Neurophysiol. 48:1573-1626, 1982.

Syka J, Popelar J, Kvasnak E, Astl J. Response properties of neurons in the central nucleus and external and dorsal cortices of the inferior colliculus of the guinea pig. Exp. Brain Res. 133:254266, 2000.

VATER M, Kossl M, Horn AKE. GAD- and GABA-immunoreactivity in the ascending auditory pathway of the horseshoe and mustache bats. J. Comp. Neurol. 385:183-206, 1992.

WAGNER T. Lemniscal input to identified neurons of the central nucleus of mouse inferior colliculus: an intracellular brain slice study. Eur. J. Neurosci. 8:1231-1239, 1996.

Wenstrup JJ, Leroy SA. Spectral integration in the inferior colliculus: role of glycinergic inhibition in response facilitation. $\mathrm{J}$. Neurosci. 21:RC124 (1-6), 2001.

Wenstrup JJ, Mittmann DH, Grose CD. Inputs to combinationsensitive neurons of the inferior colliculus. J. Comp. Neurol. 409:509-528, 1999.

WU SH, KeLly JB. In vitro brain slice studies of the rat's dorsal nucleus of the lateral lemniscus. I. Membrane and synaptic response properties. J. Neurophysiol. 73:780-793, 1995.

YAN J, Suga N. The midbrain creates and the thalamus sharpens echo-delay tuning for the cortical representation of target-distance information in the mustached bat. Hear. Res. 93:101-110, 1996.

YANG L, Evans MS, FAINGOld CL. Synaptic response patterns of neurons in the cortex of rat inferior colliculus. Hear. Res. 137:15-28, 1999.

YIN TCT, Hirsch JA, Chan JCK. Responses in the cat's superior colliculus to acoustic stimuli. II. A model of interaural intensity sensitivity. J. Neurophysiol. 53:746-758, 1985.

Zhang HM, Kelly JB. AMPA and NMDA receptors regulate responses of neurons in the rat's inferior colliculus. J. Neurophysiol. 86:871-880, 2001. 